assessed after two weeks. Clinical "success" was defined as complete freedom from symptoms, and sigmoidoscopic "success" was defined as a definite improvement in the sigmoidoscopic appearances.

By both these criteria, combined corticosteroid treatment emerged as superior to sulphasalazine for the limited purpose which this therapeutic trial was designed to test.

\section{REFERENCES}

Armitage, P. (1957). Biometrika, 44, 9.

Bargen, J. A (1955). Sth. med. J. (Bgham. Ala.), 48, 192.

Baron, J. H., Connell, Lennard-Jones, J. E, and Jones, F. A. (1962). Lancet, 1, 1094.

Hench, P. S., Kendall, E. C., Slocumb, C. H., and Polley, H. F. (1949). Ann. rheum. Dis., 8, 97.

Lagercrantz, R. (1949). Acta paediat. (Uppsala), Suppl. No. 75, p. 89

_ (1955). Ibid., 44, 302.
Lennard-Jones, J. E., Longmore, A. J., Newell, A. C., Wilson, C. W. E., and Jones, F. A. (1960). Gut, 1, 217

Moertel, C. G., and Bargen, J. A. (1959). Ann. intern. Med., 51 879 .

Morrison, L. M. (1952). Gastroenterology, 21, 133.

(1953). J. Amer. med. Ass., 151, 366.

Svartz, N. (1942). Acta med. scand., 110, 577.

(1948). Ibid., 130, Suppl. No. 206, p. 465

(1954). Gastroenterology, $26,26$.

(1956). Gastroenterologia (Basel), 86, 683

(1960). Groceedings of International Congress of Gastro

enterology, Leyden. Published by Excerpta Medica.

Truelove, S. C. (1956). Brit. med. J., 2, 1267.

- (1957). Ibid., 1, 1437.

(1958). Ibid., 2, 1073.

(1960). Ibid., 1, 464.

and Witts, L. J. (1954). Ibid., 2, 375.

$=-(1955)$. Ibid., 2, 1041.

Watkinson, G. (1958). Ibid., 2, 1077.

(1960). Proceedings of International Congress of Gastroenterology, Leyden. Published by Excerpta Medica.

\title{
INTRAVENOUS UREA AS A DIURETIC IN PROSTATECTOMY
}

BY

\author{
G. B. McKELVIE, M.B., F.R.C.S.Ed. \\ Senior Surgical Registrar, Stirling Royal Infirmary
}

The two greatest hazards of prostatectomy are generally acknowledged to be post-operative haemorrhage and infection. The Lancet (1956) stated that there were " three potential killers" after prostatectomy-bleeding, infection, and "collapse of the patient's morale." The third of these causes is probably the result in large measure of the first two.

It was thought likely that if a large urinary output could be achieved safely in the immediate postoperative period a big contribution to the elimination of these hazards would be made. With this end in view it was decided to perform a series of prostatectomies using intravenous urea as a diuretic combined with a simple closed-drainage system.

\section{Methods and Materials}

In a period of 13 months up to July, 1962, 161 prostatectomies have been performed in the urological unit at Stirling Royal Infirmary and Clackmannan County Hospital. They presented either as emergencies with retention of urine (70 with acute retention and 20 with chronic retention) or were admitted from the waiting-list after previous investigation at an out-patient clinic (71 cases).

It is noteworthy that only four patients in this 13month period were not considered fit to undergo prostatectomy. All four died within a few hours or days of admission from causes not directly related to retention of urine. The operability rate was therefore $97.5 \%$.

The average age of the patients was 71, ranging from 56 to 91 , with 29 octogenarians in the series. As no selection was made, the series therefore contains a representative quota of patients suffering from vascular disease, hypertension, chronic bronchitis, and anaemia. Indeed, there was a definite history of previous myocardial infarction in 20 cases -17 suffered from congestive cardiac failure (eight controlled with digitalis and nine noted after admission) and in three there had been cerebral thrombosis with only partial recovery of function. Other complicating factors included seven patients with mild diabetes, 19 with a history of duodenal ulceration, one admitted with acute retention of urine and subacute intestinal obstruction which had to be dealt with first, one had carcinoma of the oesophagus brought to notice after operation, one had previously undergone nephrectomy for staghorn calculus, and one was known to have gross bilateral hydronephrosis. The type of operation performed was retropubic in 133 cases, transvesical in 15 , and perurethral in 13.

Immediate prostatectomy was performed in 48 of the 70 patients who presented with acute retention of urine and in 4 of the 14 who presented with chronic retention with overflow. The operation and histological findings were : benign hypertrophy in 143 cases, carcinoma in 12 , fibrous prostate in 5 , and large prostatic abscess in 1.

In all cases general anaesthesia was used and blood transfusion was given to replace loss at the time of operation. In 39 cases blood transfusion was not required, 67 had 1 pint $(570 \mathrm{ml}$.), 44 had 2 pints $(1,140$ $\mathrm{ml}$.), the remaining 11 having 3 pints $(1,700 \mathrm{ml}$.) or more, either on account of severe preoperative anaemia or rather more than average loss at operation.

Antibiotics were not used as a routine, but where infection was known to be present or where respiratory complications were expected the appropriate antibiotic was given. Eighty-nine patients had no antibiotic at all.

The Routine.-In 110 cases $3,000 \mathrm{ml}$. of $4 \%$ urea in $5 \%$ dextrose " ureaphil" was given intravenously in 24 hours for 72 hours post-operatively. In three cases where troublesome bleeding was expected this was increased to $4,000 \mathrm{ml}$. in 24 hours; the remaining 48 had $3,000 \mathrm{ml}$. in 24 hours for 48 hours post-operatively. A "polythene" catheter of the "intracath" type was found to be satisfactory in keeping the intravenous transfusion running for 72 hours with the minimum of trouble, and when fitted with a "plexitron" adaptor allowed blood tranusfusion to be given simultaneously. The transfusion of urea was started in the theatre as soon as the prostate gland had been removed.

The urethral catheter used was a Foley self-retaining type made of plastic, and at the end of operation, after washing the bladder with a weak solution of chlorhexidine, this was connected to a gamma-ray sterilized disposable plastic bag of $1,500-\mathrm{ml}$. capacity, thereby 
setting up a very simple but efficient system of closed drainage.

The following investigations were made and the results recorded.

Urine.-(a) Culture: (1) On admission by mid-stream urine or catheter specimen of urine in theatre just before operation in those cases submitted to immediate prostatectomy ; (2) by C.S.U. immediately before operation in cases with a period of catheter drainage ; (3) daily by C.S.U. or M.S.U. for one week postoperatively and on the day before discharge from hospital; (4) M.S.U. at review after one month. (b) Urea concentration: daily for one week postoperatively. (c) Accurate intake and output charts.

Blood. - (a) Haemoglobin estimation and crossmatching on admission. (b) Blood urea: On admission, on the day before operation in those who had a period of catheter drainage, daily for a week post-operatively and on the day before discharge from hospital, and at monthly review. (c) Electrolytes: serum sodium, potassium, and chloride were estimated on the day of admission and on the third post-operative day. (d) Culture: (1) Taken during the operation immediately after removal of the prostate, and (2) immediately after removal of the urethral catheter.

Others.-(a) In addition to routine histology of the prostate the prostatic cavity or adenoma was swabbed and culture made from this swab. (b) Intravenous pyelography (I.V.P.) in some of the waiting-list patients and where indicated in patients presenting with haematuria.

\section{Results}

There were seven deaths in the series, an operative mortality of $4.3 \%$. In all cases the cause of death was verified at necropsy. Details of the seven fatalities are given below.

Case 1.-Man aged 89. Acute retention of urine with bladder distended to umbilicus. Grossly arteriosclerotic, B.P. $210 / 150$. Diabetic on insulin. Blood urea $65 \mathrm{mg} . / 100$ $\mathrm{ml}$. Gibbon's catheter used to relieve retention on admission but haematuria noted to continue after catheterization. Cystoscopy performed and bladder neoplasm could not be excluded, gross prostatic hypertrophy noted. Urine sterile on admission, but Escherichia coli present after 14 days of catheter drainage. Transvesical prostatectomy performed. Satisfactory output of urine attained in spite of excess bleeding. Died suddenly on third post-operative day. Necropsy showed an antero-septal myocardial infarction. The kidneys were granular and contracted but free of infection.

Case 2.-Man aged 74. Chronic retention with overflow. Obese and arteriosclerotic. B.P. 260/130. Blood urea 163 $\mathrm{mg} . / 100 \mathrm{ml}$. Retropubic prostatectomy performed. Made satisfactory post-operative progress, blood urea rising only to $184 \mathrm{mg}$. and falling to $52 \mathrm{mg}$. on the seventh post-operative day. The urinary output in the second 24 hours was 7,200 $\mathrm{ml}$. The catheter was removed on the fifth day but the patient tended to have poor control of micturition. Proteus vulgaris was cultured on the seventh and subsequent days. He remained incontinent, and a bougie was passed on the 14th post-operative day to exclude contracture of bladder neck. After this his condition deteriorated rapidly; he developed pyrexia, became comatose, and died on the 16th post-operative day. Necropsy showed gross bilateral hydroureter and hydronephrosis with infection.

Case 3.-Man aged 76. Chronic retention of urine with overflow. Congestive cardiac failure; arteriosclerotic and diabetic. B.P. $200 / 140$. Blood urea $110 \mathrm{mg} . / 100 \mathrm{ml}$ Gibbon's catheter passed on admission. Retropubic prostatectomy three days after admission, when blood urea was $70 \mathrm{mg}$. and diabetes stabilized. Immediate postoperative condition was satisfactory; no pyrexia, good urinary output, sterile urine. Blood urea fell to $48 \mathrm{mg}$. On the ninth post operative day he developed pulmonary oedema and died the next day, in spite of treatment with digoxin and bendrofluazide. Necropsy showed death to be due to congestive cardiac failure. The kidneys were granular and contracted, but there was no sign of infection.

Case 4.- Man aged 80. Acute retention of urine; arteriosclerotic; history of myocardial infarction. B.P. $220 / 130$. Blood urea $70 \mathrm{mg} . / 100 \mathrm{ml}$. Immediate retropubic prostatectomy performed. Blood urea rose to $275 \mathrm{mg}$. on third post-operative day but fell to $38 \mathrm{mg}$. on eighth day. Developed right-sided hemiplegia on fourth day and slowly became comatose over the next few days. Died on ninth post-operative day. Fluid intake maintained with $5 \%$ dextrose intravenously after three days. Necropsy showed cause of death to be cerebral thrombosis and hypestatic pneumonia. The kidneys were granular and contracted but showed no sign of infection.

Case 5.-Man aged 73, from the waiting-list. Arteriosclerotic. B.P. $180 / 110$. Retropubic prostatectomy. Blood urea $35 \mathrm{mg} . / 100 \mathrm{ml}$; $160 \mathrm{mg}$. on third post-operative day, and $27 \mathrm{mg}$. on fifth day. Good output; good progress until he slipped and fell going to the toilet on sixth day. After this he developed left-sided lobar pneumonia with consolidation also at the right base. Pyrexia developed and he became semicomatose. Tracheostomy performed on 12th day to ease respiratory difficulty. He was recatheterized on 10th day as he had become incontinent. Improved after tracheostomy for one week, but thereafter gradually deteriorated, dying on 26th post-operative day. The urine remained sterile throughout. Necropsy showed gross consolidation of both lungs, death being due to lobar pneumonia. There was no sign of renal infection.

Case 6.-Man aged 84. Chronic retention of urine with overflow. In spite of age, general condition appeared very good. Gibbon's catheter passed on admission, when blood urea was $275 \mathrm{mg} . / 100 \mathrm{ml}$. Retropubic prostatectomy performed 48 hours after admission. Post-operative course uncomplicated; no pyrexia, good output. Blood urea fell to $58 \mathrm{mg}$. on fifth post-operative day, when he was passing urine spontaneously. On the sixth day he died suddenly. Necropsy showed the cause of death to be a massive posterior myocardial infarction. Kidneys and prostatectomy site were clear of infection.

Case 7.-Man aged 81. Acute retention of urine while in medical unit being treated for duodenal ulcer with vomiting. Grossly arteriosclerotic with aortic aneurysm. Gastric symptoms had subsided when he developed retention of urine. Blood urea, $148 \mathrm{mg} . / 100 \mathrm{ml}$. Gibbon's catheter passed for 48 hours prior to retropubic prostatectomy. Post-operative course very satisfactory until eighth day, when he suddenly collapsed and was found to have a massive haematemesis and melaena. He died in spite of blood transfusion. Necropsy showed the cause of death to be a large duodenal ulcer with an arteriosclerotic patent vessel in its base. The aortic aneurysm was noted and in addition there was an aneurysm of the right common iliac artery. Blood urea was $42 \mathrm{mg}$. on day before death. The urinary tract showed no sign of infection.

The remaining 154 patients made a satisfactory recovery. No patients suffered from clot retention. The urinary output charts testify to the efficacy of $4 \%$ urea given intravenously as a diuretic. Urinary outputs of over $3,000 \mathrm{ml}$. were achieved in the first 24 hours by 146 patients and all had outputs in excess of $3,000 \mathrm{ml}$. in the second and third 24 hours. Of the eight who did not have outputs of $3,000 \mathrm{ml}$. in the first 24 hours, $2,300 \mathrm{ml}$. was the lowest recorded figure.

In only seven patients was there temporary cistruction to the drainage system, not caused by clots but due 
in two cases to bursting of the Foley self-retaining bag with subsequent blocking of the catheter eye. In only these seven was bladder lavage employed to ensure that the system was working satisfactorily after replacement of the catheter. When catheter drainage gave trouble after the first 24 hours it was found that a Gibbon catheter provided adequate drainage, because the output was large enough and the blood so diluted that a widerbore catheter was not required. A Gibbon catheter was so used on five occasions.

Three patients had a minor degree of secondary haemorrhage on the eighth, ninth, and tenth days postoperatively. The bleeding cleared spontaneously without interrupting convalescence and without the necessity for catheterization. Two had a more severe haemorrhage necessitating catheterization for 24 hours after bladder lavage but not severe enough to require blood transfusion.

\section{Blood Urea}

The pre-operative blood urea did not affect the efficiency of the urea as a diuretic.

Eighty-seven patients had levels of less than $40 \mathrm{mg}$./ $100 \mathrm{ml}$. on admission, and only two of these were over $40 \mathrm{mg}$. (43 and $45 \mathrm{mg}$.) on discharge at 12 days, and both were below $40 \mathrm{mg}$. when checked at one month. Forty-five had levels between 40 and $60 \mathrm{mg}$. on admission, and of this group all were below $40 \mathrm{mg}$. on discharge from hospital. Twenty-two had levels ranging from 64 to $275 \mathrm{mg}$., and only two above $40 \mathrm{mg}$. on discharge (56 and $108 \mathrm{mg}$.). One of these was below $40 \mathrm{mg}$. at one monthly review, but the other remained elevated at $100 \mathrm{mg}$. This patient is known to have gross bilateral hydronephrosis with no function shown on I.V.P. His admission blood urea was $122 \mathrm{mg}$.

Study of the daily post-operative blood urea estimations revealed four distinct patterns of behaviour (see Chart).

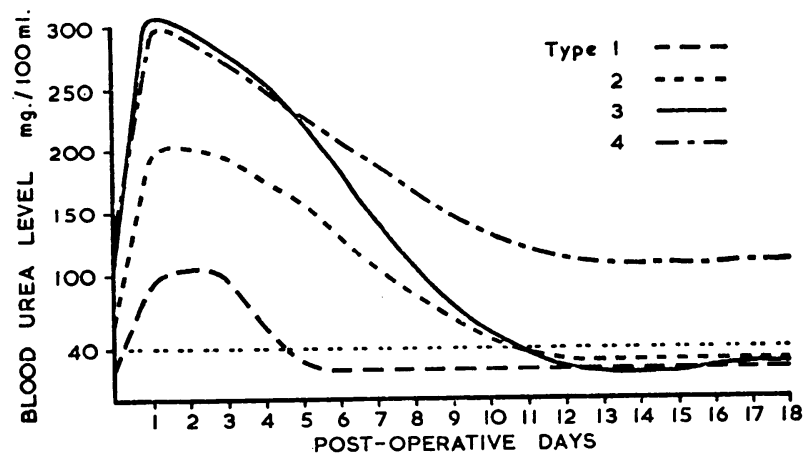

Blood urea estimations showing four distinct types of behaviour.

Type 1.-Where the blood urea is normal, or only slightly raised on admission, there is a rise to $80-120 \mathrm{mg}$. for the two or three days they are given urea and then a rapid fall to normal on the fifth or sixth post-operative day. Eighty-nine cases produced this type of curve.

Type 2.-Where the blood urea is normal or near normal there is a rise higher than expected, taking longer (6 to 12 days) to return to normal than type 1 . Forty-four fell into this group.

Type 3.- Where the blood urea is high at operation or before catheter drainage is instituted pre-operatively, the blood urea may become very high $(250-400 \mathrm{mg}$.) before faling more slowly to normal in a period 8 to 12 days. Twenty-one cases showed this type of curve.

Type 4.-Those presenting with a high blood urea which rises higher and falls slowly to the previous high estimation.
Only one produced such a curve; this patient was known to have bilateral hydronephrosis and pyelonephritis.

The type of curve produced by an individual patient is thought to give a reasonable assessment of renal function. I.V.P. was performed preoperatively in 52 of the patients, but all except one showed excretion at five minutes. Twenty-nine were shown subsequently to have type 1 curves, 18 had type 2 curves, and four had type 3 curves. The patient showing no excretion on I.V.P. was the single example of the type 4 curve.

\section{Urine Urea}

The urine urea concentration frequently rose to $3 \%$ and $4 \%$ in patients with a type 1 curve, and where it failed to do so it was noted that there was a large oral intake of fluid in addition to the intravenous urea, with a very large urinary output therefore resulting.

Patients showing curves of types 2, 3, and 4 rarely produced urines containing urea in excess of $2 \%$. Where water diuresis continued after cessation of the intravenous urea, urinary urea concentrations were mostly in the range from $0.5 \%$ to $2 \%$.

When assessing the value of intravenous urea and the diuresis it produced in relation to infection, it has been found helpful to divide the 154 patients into four groups. (1) Patients with a sterile urine on admission, showing no growth on cultures at any time during their stay in hospital, and having sterile urines at monthly review. (2) Patients who had a sterile urine on admission but had periods of catheter drainage ranging from 3 to 60 days, and who had infected urines before prostatectomy. (3) Patients with a sterile urine on admission whose urine subsequently showed a growth on culture postoperatively. (4) Patients whose urine was infected on admission.

\section{Group 1}

This, by far the largest group, contained 118 casesthat is, $70 \%$ of the whole series and $81 \%$ of those admitted with sterile urines. Of these, 37 had immediate prostatectomy for retention ( 35 acute and two chronic) and 18 had prostatectomy performed within 48 hours of passing a Gibbon catheter. Three had periods of 10 to 16 days' pre-operative catheterization with a Gibbon catheter. Only two had been catheterized once before admission.

In only two patients in this group was there any interference with the post-operative drainage system, and this was caused by the Foley self-retaining bag slipping into the large prostatic cavity, with blockage of the eye. Both catheters were replaced by Gibbon catheters, and their course was thereafter uneventful. In none was post-operative catheter drainage continued for more than six days ( 25 for three days, 56 for four days, 34 for five days, and 3 for six days).

Culture from the prostate showed a growth of Staphylococcus albus on six occasions, and one blood culture at the time of operation showed the same organism. It is thought that these positive cultures were probably the result of skin contamination of the swab.

There was no serious post-operative complication.

Forty-two were given " crystamycin " for five to seven days as a prophylactic or for the treatment of minor degrees of post-operative respiratory infection; 76 had no antibiotic at all. One patient who had a history of mitral stenosis developed congestive cardiac failure on the second post-operative day and was given $8 \%$ urea 
for 24 hours; this, combined with digoxin and bendrofluazide, effected a startling recovery.

Ninety-four patients were discharged between the eleventh and fourteenth post-operative days and four on the sixteenth day; the remainder were detained longer on account of home circumstances.

\section{Group 2}

This group comprised seven patients who were seen with acute or chronic retention of urine. They were catheterized for periods ranging from 3 to 60 days preoperatively for various reasons-for example, fractured ribs with bronchopneumonia, perforated gastric ulcer, subacute intestinal obstruction, investigation of anaemia, haematuria-and although the urine was sterile on admission it was infected before operation.

Table I shows the infecting organisms, the result of blood cultures and prostatic cultures. There were two perurethral operations in this group and therefore no

\begin{tabular}{|c|c|c|c|c|c|c|c|}
\hline \multirow{2}{*}{ Organism } & \multirow{2}{*}{$\begin{array}{l}\text { No. } \\
\text { of } \\
\text { Cases }\end{array}$} & \multicolumn{2}{|c|}{$\begin{array}{c}\text { Blood } \\
\text { Culture }\end{array}$} & \multirow{2}{*}{$\begin{array}{c}\text { Prostate } \\
\text { Culture }\end{array}$} & \multirow{2}{*}{$\begin{array}{c}\text { Anti- } \\
\text { biotics }\end{array}$} & \multirow{2}{*}{$\begin{array}{l}\text { Positive } \\
\text { Culture } \\
\text { on Dis- } \\
\text { charge }\end{array}$} & \multirow{2}{*}{$\begin{array}{c}\text { Positive } \\
\text { Culture } \\
\text { at } \\
1 \mathrm{mh}\end{array}$} \\
\hline & & Op. & Cath. & & & & \\
\hline $\begin{array}{l}\text { Pr. vulgaris .. } \\
\text { E. coli } \quad . \\
\text { Staph. aureus } \\
\text { Str. faecalis .. }\end{array}$ & $\begin{array}{l}3 \\
2 \\
1 \\
1 \\
\end{array}$ & $\begin{array}{l}\overline{1} \\
1 \\
\end{array}$ & $\overline{1}$ & $\begin{array}{l}1 \\
2 \\
1 \\
-\end{array}$ & $\begin{array}{l}3 \\
1 \\
1 \\
1 \\
\end{array}$ & $\begin{array}{l}2 \\
1 \\
\\
\end{array}$ & $\begin{array}{l}2 \\
1 \\
= \\
\end{array}$ \\
\hline Total & 7 & 2 & 1 & 4 & 6 & 3 & 3 \\
\hline
\end{tabular}

prostate culture was taken. The average post-prostatectomy stay in hospital of this group was 22 days, the longest being 37 days and the shortest 13 days.

Infection had been eradicated in four patients by the time the patient was discharged. The E. coli remaining at one month was eradicated one month later by antibiotic treatment, but the two $\mathrm{Pr}$. vulgaris infections persisted in spite of antibiotic treatment. There were two wound infections-one Staph. aureus and one E. coli -in this group. The patient with Staph. aureus infection developed pyrexia on the fifth post-operative day which responded to chloramphenicol, and presumably it was due to wound infection. In no patient was there clinical evidence of " ascending pyelonephritis."

\section{Group 3}

This group comprised eight patients (Table II). Clinically they were straightforward, were apyrexial, and did not show clinical signs of infection. Three had cystoscopy performed three days before prostatectomy, and the case showing a positive culture had been catheterized four days in succession before admission to hospital. The average stay in hospital of this group was 14 days (13-15). Two of the three still showing

\begin{tabular}{|c|c|c|c|c|c|c|c|c|}
\hline \multirow{2}{*}{$\begin{array}{l}\text { Case } \\
\text { No. }\end{array}$} & \multirow{2}{*}{$\begin{array}{l}\text { Infecting } \\
\text { Organ- } \\
\text { ism }\end{array}$} & \multirow{2}{*}{$\begin{array}{c}\text { Pros- } \\
\text { tate } \\
\text { Cul- } \\
\text { ture }\end{array}$} & \multicolumn{2}{|c|}{$\begin{array}{l}\text { Blood } \\
\text { Culture }\end{array}$} & \multirow{2}{*}{$\begin{array}{c}\begin{array}{c}\text { Day of } \\
\text { Ist } \\
\text { Appear- } \\
\text { ance of } \\
\text { Organism }\end{array}\end{array}$} & \multirow{2}{*}{$\begin{array}{c}\text { Culture } \\
\text { on } \\
\text { Discharge }\end{array}$} & \multirow{2}{*}{$\begin{array}{c}\text { Culture } \\
\text { at } \\
1 \mathrm{mth}\end{array}$} & \multirow{2}{*}{$\begin{array}{l}\text { Anti- } \\
\text { biotic } \\
\text { Given }\end{array}$} \\
\hline & & & Op. & Cath. & & & & \\
\hline $\begin{array}{l}1 \\
2 \\
3 \\
4 \\
5 \\
6 \\
7 \\
8\end{array}$ & 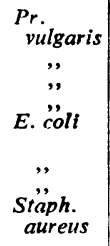 & $\begin{array}{l}\bar{Z} \\
\bar{Z} \\
\text { coli } \\
\bar{Z} \\
-\end{array}$ & $\begin{array}{l}= \\
= \\
= \\
= \\
-\end{array}$ & $\begin{array}{l}= \\
= \\
z \\
z \\
-\end{array}$ & $\begin{array}{r}5 \text { th } \\
5 \text { th } \\
6 \text { th } \\
7 \text { th } \\
7 \text { th } \\
11 \text { th } \\
6 \text { th } \\
12 \text { th }\end{array}$ & $\begin{array}{c}\text { Positive } \\
\text { Negative } \\
\text { Positive } \\
\quad, \\
\text { Negative } \\
\text { Positive } \\
\text { Negative } \\
\text { Positive }\end{array}$ & $\begin{array}{c}\text { Positive } \\
\text { Negative } \\
\text { Positive } \\
\text { Negative } \\
\text { Positive } \\
\text { Negative } \\
\text {," }\end{array}$ & $\begin{array}{l}\text { Yes } \\
\text { No } \\
\text { ", } \\
\text { Yes } \\
\text { No } \\
\text { Yes } \\
\text {," }\end{array}$ \\
\hline
\end{tabular}

positive cultures at monthly follow-up have since had their infection eradicated.

\section{Group 4}

Twenty-one had an infected urine on admission (Table III). There were five perurethral operations in this group and the prostate was not cultured in these cases. In one patient, after withdrawal of the catheter on the fourth post-operative day, pyrexia suggestive of

TABLE III

\begin{tabular}{|c|c|c|c|c|c|c|c|}
\hline \multirow{2}{*}{ Organism } & \multirow{2}{*}{$\begin{array}{c}\text { No. } \\
\text { of } \\
\text { Cases }\end{array}$} & \multicolumn{2}{|c|}{$\begin{array}{c}\text { Blood } \\
\text { Culture at }\end{array}$} & \multirow{2}{*}{$\begin{array}{l}\text { Prostate } \\
\text { Culture }\end{array}$} & \multirow{2}{*}{$\begin{array}{c}\text { Anti- } \\
\text { biotics }\end{array}$} & \multirow{2}{*}{$\begin{array}{l}\text { Positive } \\
\text { Culture } \\
\text { on Dis- } \\
\text { charge }\end{array}$} & \multirow{2}{*}{$\begin{array}{c}\text { Positive } \\
\text { Culture } \\
\text { at } \\
1 \mathrm{mth}\end{array}$} \\
\hline & & Op. & Cath. & & & & \\
\hline \multirow{3}{*}{ 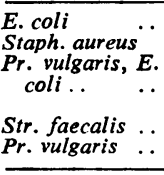 } & $\begin{array}{r}13 \\
2\end{array}$ & 6 & 1 & 11 & $\begin{array}{r}12 \\
2\end{array}$ & 8 & 2 \\
\hline & 1 & - & - & - & 1 & 1 & E. coli \\
\hline & $\begin{array}{l}4 \\
1\end{array}$ & 1 & $=$ & $\begin{array}{l}1 \\
1\end{array}$ & $\begin{array}{l}4 \\
1\end{array}$ & $=$ & 二 \\
\hline Total .. & 21 & 7 & 1 & 14 & 20 & 9 & 3 \\
\hline
\end{tabular}

ascending pyelonephritis developed. The temperature subsided with tetracycline in a few days, and this patient was subsequently found to be the one who had a positive blood culture on withdrawal of the catheter. The average post-operative hospital stay in this group was 14 days (11-17).

Nine patients had infected urines on discharge but were asymptomatic, and only three persisted at one month, including the patient with bilateral hydronephrosis and the one with the large prostatic abscess.

\section{Comment}

Considering groups 1,2 , and 3 as a whole-that is, all patients admitted with sterile urines-it will be seen that of 132 patients admitted 84 were discharged with sterile urines, an infection rate of $6 \%$, and if cases with sterile urines at operation, groups 1 and 3, were considered alone, the infection rate on discharge is $4 \%$. In only one case, in group 4, was there any clinical indication of renal infection as distinct from urinary infection.

One result of this trial not foreseen before it started was the complete disappearance of post-operative disorientation, too commonly encountered after prostatectomy in old arteriosclerotic subjects, with the result that patients were able to co-operate to their full ability with the nursing and medical staff.

Two patients developed calf-vein thrombosis but embolic phenomena were not noted. One patient developed a cerebral thrombosis with left-sided paresis which almost fully recovered. Thrombophlebitis at the site of the drip was recorded in 49 patients, but in no case did it give rise to serious trouble, settling spontaneously within 24 to 48 hours. There was also a remarkable absence of post-operative respiratory infections of a serious nature, but it must be admitted that this last observation is a clinical impression only. In only two patients was there troublesome wound infection (both in group 2). Diarrhoea for two days was encountered in three patients.

\section{Discussion}

It is a generally accepted principle that after prostatectomy a high outflow of urine is desirable. This obviates the necessity for bladder lavage, which may 
cause discomfort and which carries the risk of introducing infection. Without the need for bladder lavage a proper evaluation of blood loss and acurate measurement of urine output may be made.

It is, however, difficult to achieve a high urine output in the presence of post-operative antidiuresis and sodium retention, and it is well known that attempts to hydrate patients in this period will produce water retention (Dudley et al., 1954; Wangensteen and Zimmerman, 1952). It is of course during this antidiuretic postoperative phase that a high urine outflow would be most desirable, to dilute blood oozing from a prostatic cavity and prevent clot formation.

It is pointed out by the Lancet (1956) that " it is by no means impossible to bully the enfeebled elderly patient into mild water intoxication when 'the pressing of fluids' by mouth degenerates into barrack-room drill." This state of affairs may also be easily produced by treatment with intravenous dextrose, and the mild water intoxication resulting is probably the major cause of post-operative disorientation which gives rise to the forbidding picture painted by the Lancet (1956) of " half a dozen uprooted, prostatectomized old men "climbing up the wall" "at night.

Antidiuresis, however, does not mean that urine volume necessarily has to be low. It merely implies that the ratio of solute to water in the urine is increased, so that concentration of solutes in the urine is higher than in the serum. It is well known that during antidiuresis the urine volume is a direct result of the amount of solutes excreted (Dudley et al., 1954; Wangensteen and Zimmerman, 1952 ; Kerrigan et al., 1955 ; Schlegel et al., 1957).

Sodium chloride is a solute, but since sodium retention often prevails after surgery, owing to reabsorption in the proximal tubule of the kidney, it is consequently not available for excretion in the urine.

It has been shown by Schlegel et al. (1957) that antidiuresis following surgery can be completely overcome by the administration of urea as $4 \%$ solution in $5 \%$ dextrose, that it will not lead to dehydration, and that it will maintain homoeostasis in regard to water and electrolytes in patients with relatively normal renal function. These authors demonstrated that losses of weight found in patients receiving $4 \%$ urea added to intravenous fluids approximate to what apears to be a normal loss in a patient without food for a 24-hour period.

The average loss of weight after surgery reported by Paquin (1955) and commented upon by Moore (1955) is much less than what would be encountered in a normal individual deprived of food for 24 hours.

It has also been shown by Jorgensen and Schlegel (1959) that the addition of $4 \%$ urea to intravenous fluids prevents sodium retention, the suggestion being made that this result is due to the maintenance of haemostasis with regard to water. Where there was renal damage or cortisone was given, sodium retention was seen in spite of unchanged serum sodium levels and a good urinary output.

Urea is an excellent diuretic, and it has been shown that it will distribute rapidly over total body water except the C.S.F. (Kennedy et al., 1962) and that this does not cause any distortion of the body-fluid compartments (McDowell et al., 1955), whereas mannitol causes an expansion of the extracellular fluid (Seldin and Tarail, 1949). For this reason urea has been used in the treatment of oedema in advanced heart failure by Crawford and McIntosh (1925) and more recently by Papp and Shirley Smith (1957).

Schlegel et al. (1961) have shown that urea is bacteriostatic to the common organisms causing urinary infection in $4 \%$ and $2 \%$ concentrations, and in his excellent article on pyelonephritis Schlegel (1961) suggests that urea concentration in the kidney is "nature's built-in defence" against infection and that a water diuresis weakens this defence system.

This trial, using $4 \%$ urea in $5 \%$ dextrose routinely after prostatectomy, represents a practical aplication of these facts in order to obtain a large urinary outflow when it is most essential-that is, in the immediate post-operative period.

In all patients a diuresis has been achieved in the post-operative antidiuretic phase, even those whose renal function was impaired, as suggested by a high blood-urea level in many cases and on post-mortem examination of the kidneys of those patients who died.

Three of these patients had granular contracted kidneys and one had gross hydronephrosis, but all produced a high urinary outflow post-operatively. Diuresis was also achieved easily in the patients suffering from congestive cardiac failure; and in one patient whose failure developed on the second post-operative day raising the concentration of urea to $8 \%$ brought an almost dramatic recovery. The ability to cope with this notoriously difficult type of patient is a great advantage and should result in a higher operability rate.

Even after the antidiuretic phase had passed, many patients cannot drink copious amounts of water on account of digestive upset, and the continuation of intravenous therapy with urea is a safe method of providing fluid. It is interesting to note that there were 19 patients in this series who either suffered from duodenal ulceration or who had been operated upon in the past for this condition.

The administration of urea was not a factor contributing to any of the deaths in this series. It is well known that the mortality in prostatectomy rises with age. In a series of 757 cases Millin et al. (1949) found that below 70 years of age the mortality was less than $2 \%$ while at 80 and over it was nearly $20 \%$.

In the present series there were no deaths in patients below the age of 70 , and the total mortality rate of $4.3 \%$ compares favourably with other series recently reported. It has been recorded by Ellis and Leatherdale (1958), Salvaris (1960), and Scorer and Knight (1962) that mortality is higher if retention has occurred. Table IV shows a comparison of four recently reported series with the present one taking into account operability rate and retention rate.

No patient in the series showed any significant abnormality of the serum electrolytes (sodium, potassium, chloride) either before operation or when estimated on the third post-operative day, but in three cases clinical dehydration before operation was rectified

\begin{tabular}{|c|c|c|c|c|}
\hline Author & & $\begin{array}{l}\text { Incidence } \\
\text { of Acute } \\
\text { Retention }\end{array}$ & $\begin{array}{c}\text { Operability } \\
\text { Rate }\end{array}$ & Mortality \\
\hline $\begin{array}{l}\text { Ellis and Ieatherdale (1958) } \\
\text { Salvaris }(1960) \quad . . \\
\text { Tagart }(1961) \quad . . \\
\text { Scorer and Knight (1962) } \\
\text { Present series } \quad . .\end{array}$ & $\begin{array}{l}\cdots \\
\cdots \\
\cdots \\
\cdots\end{array}$ & $\begin{array}{l}75 \% \\
25 \% \\
44 \% \\
70 \% \\
56 \%\end{array}$ & $\begin{array}{c}94 \% \\
\text { Not known } \\
97 \% \\
64 \% \\
97.5 \%\end{array}$ & $\begin{array}{l}10 \cdot 2 \% \\
4.2 \% \\
4.2 \% \\
6.2 \% \\
4 \cdot 3 \%\end{array}$ \\
\hline
\end{tabular}


by giving extra fluid as saline and dextrose. Three patients who had severe diarrhoea for 24 hours on the second post-operative day were also given extra fluid in the form of saline. It became evident from these patients that although $4 \%$ urea would not cause dehydration it will not correct pre-existing dehydration. Any such deficit requires oral or intravenous therapy in the usual way.

It is interesting that at the time the three patients developed diarrhoea they had very high blood urea levels $(300,325$, and $275 \mathrm{mg} . / 100 \mathrm{ml}$.). It is suggested (Samson Wright, 1952) that a high concentration of urea in the intestinal mucosa may decompose to give ammonia, which is irritant to the mucosa, causing diarrhoea. No pathogenic organisms were cultured from the stools of these patients, nor had they impacted faeces giving rise to spurious diarrhoea.

All patients were encouraged to take oral fluids liberally after the first 24 hours. This combined with intravenous urea gave massive outputs in many cases.

The remarkable absence of post-operative disorientation is attributed to the absence of water intoxication. The effect of this on the patient's ability to co-operate and on the good morale of the ward as a whole would alone justify the use of intravenous urea.

It may be that the prevention of circulatory overloading, sodium retention, and subsequent mild oedema has contributed to a low rate of wound infection and the absence of serious post-operative respiratory complications.

The contribution of urea diuresis to the control of urinary infection has been invaluable. Established renal infection may be very difficult to eliminate and therefore measures to prevent infection are imperative.

The introduction of infection into a sterile urinary tract undoubtedly arises in the great majority of patients through the urethra. This may result in a variety of ways, including faulty sterilization of instruments, errors in technique, infection carried by a catheter from the urethra, and urethritis from an indwelling catheter; or infection may ascend along the lumen of a catheter, In this trial attention was given to all of these factors, including the sterilization of urinals (McLeod, 1958). Immediate prostatectomy is preferred, where possible, for retention of urine, and if not found possible the aim is to proceed with prostatectomy with the minimum possible preoperative catheter drainage period. This has been the practice in this unit for some years now and the majority of the practitioners in the area do not catheterize patients before sending them to hospital. If catheterization proves necessary before operation a Gibbon type is used routinely. Gibbon (1958) pointed out the value of biologically inert and water-repellent material for use in catheters, and the introduction of a plastic type Foley self-retaining catheter for postoperative use has been welcomed.

In the present series $87 \%$ of cases had sterile urines on admission, and it is noteworthy that those who became infected prior to operation had catheter drainage for periods of from 3 to 60 days. Marshall (1961) stressed the importance of a short preoperative period of catheter drainage, and pointed out the dangers of bacteriaemia arising from operation in an infected field. Marshall found an incidence of $82 \%$ positive blood cultures in 34 patients with infected urines at operation and an incidence of $12.5 \%$ positive blood cultures in 16 cases with sterile urines. In the present series, of 28 patients infected before operation (groups 2 and 4), 9 ( $32 \%)$ positive cultures corresponding to the infecting urinary organism and the organism obtained on prostatic culture were found. Only one of these patients gave a positive blood culture on the day the catheter was removed and he was the only one in the whole series with a definite clinical indication of a renal infection. All patients showing a positive blood culture at operation had antibiotics started that day or within a few days, when the urine was known to be infected with a specific organism. It might well be that the single patient who developed "ascending" pyelonephritis developed the infection from the bacteriaemia set up by the removal of the catheter, at a time when there was water diuresis only, the urea having been stopped and "nature's built-in defence" (Schlegel, 1961) removed.

In only one patient was a positive blood culture shown at the time of operation on the sterile cases. As the organism cultured was Staph. albus its significance is doubtful.

The value of a closed circuit in post-operative drainage of the bladder has already been shown (Pyrah et al., 1955). More recently Gillespie et al. (1960), Miller et al. (1958), and Tagart (1961) have shown the importance of such a system and have described devices incorporated in the system to irrigate the bladder without interrupting closed drainage. A closed circuit has been used for some years in this unit, but in order to try to simplify the routine it was decided to use gamma-ray-sterilized plastic disposable bags of $1,500-\mathrm{ml}$. capacity. As plastic bags could not be "milked" to help the passage of small blood clots their use was not fully appreciated until the introduction of a urea diuresis. This simple but excellent system of drainage has been entirely satisfactory since the start of this trial. The only time the system is open, for a very short period, is when the bag has to be changed; and before disconnecting the bag the junction is swabbed with chlorhexidine. The benefits of such a system are very evident to the nursing staff, often under strength and overworked, who no longer have to pack elaborate equipment for sterilizing and spend time in post-operative bladder lavage. The measurement of urinary output is simplified, as the capacity is indicated on the disposable bag.

It is noteworthy that Pseudomonas pyocyaneas, an organism often associated with death from infection (McLeod, 1959), has not been seen at all in this series.

It is unfortunate that there is not a similarly documented series of prostatectomies from this unit before the introduction of urea diuresis, but no doubt exists in this unit that a big step forward has been made in the treatment of patients undergoing prostatectomy.

\section{Summary and Conclusions}

A series of 161 consecutive cases undergoing prostatectomy have been given $4 \%$ urea in $5 \%$ dextrose intravenously as a diuretic.

Urea has been shown to be an excellent and safe diuretic when given by the intravenous route, successfully overcoming the antidiuresis of operative trauma.

The diuresis produced by urea has successfully eliminated problems arising from post-operative haemorrhage.

The prevention of urinary infection and especially the serious renal infection has been made possible. 
The use of urea diuresis has allowed the introduction of a very simple closed-drainage system and has eased post-operative nursing problems.

The prevention of mild water intoxication with consequent absence of post-operative disorientation is a valuable help to the patient's recovery.

The post-operative difficulties of patients suffering from congestive cardiac failure have been considerably eased.

A trial of this type cannot be done without team-work and co-operation from many people, especially when undertaken in an already busy peripheral hospital. I therefore find it a great pleasure to thank the following members of the staff. Mr. A. A. MacKelvie, in whose unit this trial was done and whose advice, criticism, and enthusiasm for the project have been invaluable. Drs. R. Rankin and P. S. Macfarlane, of the pathology department, who have so willingly helped with the increased burden of the investigations and reports on the pathological specimens. Drs. D. Beaton and A. W. Laing. of the anaesthetic staff, who, in addition to providing excellent anaesthesia, have secured many samples of blood for culture and given much help with the intravenous drips. Drs. M. Phillips and M. Fenton, the house-surgeons, who have given ungrudging help with the day-to-day care of the patients and the extra routine involved. Mr. J. Hunter and staff of the pharmacy department, who have provided the urea at any time, night or day. Finally, I wish to thank Sisters Kekstadt and Chisholm, who, along with their nurses, have provided the care and attention which has meant so much in the successful recovery of their patients.

\section{REFERENCES}

Crawford, J. H., and McIntosh, J. F. (1925). Arch. intern. Med., 36, 530

Dudley, H. F., Boling, E. A., Le Quesne, L. P., and Moore, F. D. (1954). Ann. Surg., 140, 354.

Ellis, H., and Leatherdale, R. A. L. (1958). Lancet, 2, 1189.

Gibbon, N. (1958). Brit. J. Urol., 30, 1.

Gillespie, W. A., Linton, K. B., Miller, A., and Slade, N. (1960). J. clin. Path., 13, 187.

Jorgensen, H. E., and Schlegel, J. U. (1959). Surg. Gynec. Obstet., 108, 339.

Kennedy, A. C., Linton, A. L., and Eaton, J. C. (1962). Lancet, 1,410 .

Kerrigan, G. A., Talbot, N. B., and Crawford, J. D. (1955). J. clin. Endocr., 15, 265.

Lancet. 1956, 2, 343

McDowell, M. E., Wolf, A. V., and Steer, A. (1955). Amer. J. Physiol., 180, 545

McLeod, J.' W. (1958). Lancet, 1, 394.

- (1959). Brit. J. Urol., 31, 298.

Marshall, A. (1961). Ibid., 33, 25.

Miller, A., Gillespie, W. A., Linton, K. B., Slade, N., and Mitchell, J. P. (1958). Lancet, 2, 608

Millin, T., MacAllister, Clo., and Kelly, P. M. (1949). Ibid., 1, 381 .

Moore, F. D. (1955). Ann. Surg., 141, 141.

Papp, C., and Smith, K. S. (1957). Brit. med. J., 2, 906.

Paquin, A. J., jun. (1955). Ann. Surg., 141, 383.

Pyrah, L. N., Goldie, W., Parsons, F. M., and Raper, F. P. (1955). Lancet, 2, 314 .

Salvaris, M. (1960). Med. J. Aust.. 47, 370.

Schlegel, J. U. (1961). J. Urol. (Baltimore), 86, 12

- Cuellar, J., and O'Dell, R. M. (1961). Ibid., 86, 819

- Eldrup-Jorgensen, S., and Stone, H. (1957). Ann. Surg.

Scorer, C. 'G., and Knight, S. J. (1962). Brit, med. J., 1, 141.

Seldin, D. W., and Tarail,, R. (1949). Amer. J. Physiol., 156, 160

Tagart, R. E. B. (1961). Brit. med. J., 1, 621.

Wangensteen, O. H., and Zimmerman, B. (1952). Surgery, 21. 654

Wright, S. (1952). Applied Physiology, 9th ed. Oxford Univ. Press, London.

Hungary has given Algiers equipment for a 100-bed hospital. It includes radiographic and electrocardiographic apparatus, medical instruments, 100 beds, 300 mattresses, bedding, and clothing for both doctors and nurses. The hospital is intended for the treatment of internal diseases.

\section{VESICO-VAGINAL FISTULA \\ A SERIES OF 27 CASES}

BY

I. R. McFADYEN,* M.B., M.R.C.O.G.

Lately Flight Lieutenant, R.A.F., Royal Air Force Hospital, Aden

Social ostracism can be borne, but the constant dribbling of urine wears away any morale. There are no more grateful patients than those who, cured of a vesicovaginal fistula, can return to a normal life. The lesion is rare in Britain but common in other countries. Table I shows the difference in aetiology between Western and other countries. In the latter the patients tend to be

TABLB I

\begin{tabular}{|c|c|c|c|c|}
\hline \multirow{2}{*}{ Author } & \multirow{2}{*}{ Country } & \multicolumn{3}{|c|}{ Aetiology of Vesico-vaginal Fistulae } \\
\hline & & $\begin{array}{c}\text { Gynaecol- } \\
\text { ogical }\end{array}$ & Obstetric & Others \\
\hline $\begin{array}{lc}\text { Moir (1961) } & \ldots \\
\text { Russell (1956) } & \ldots \\
\text { Miller and George } \\
\quad(1954) & \ldots \\
\text { Foda (1959) } & \ldots \\
\text { Werneck (1950) } & \ldots\end{array}$ & $\begin{array}{l}\text { Britain } \\
\text { Britain } \\
\text { U.S.A. } \\
\text { Egypt } \\
\text { S. America }\end{array}$ & $\begin{array}{c}145 \\
30 \\
232 \\
25^{*} \\
16\end{array}$ & $\begin{array}{r}62 \\
19 \\
43 \\
191 \\
333\end{array}$ & $\begin{array}{r}18 \\
1 \\
17 \\
4 \\
7\end{array}$ \\
\hline
\end{tabular}

* Includes those due to caesarean section but not those due to neoplasm or radium.

resistant to antenatal care and to complain only of major gynaecological symptoms.

Material.-The present series of 27 vesico-vaginal fistulae were seen in women of Southern Arabia. They were treated in Aden, either at the R.A.F. hospital or the Queen Elizabeth Hospital, and were only part of those treated in the colony over a two-year period. Two of the patients were brought to Aden in labour and were delivered at the maternity clinic; the other pregnancies and deliveries took place in up-country villages.

\section{Aetiology}

Table II shows that 21 of these patients laboured for over 48 hours and Table III shows in more detail the length of labour. Cephalopelvic disproportion is a

TABLE II

\begin{tabular}{|c|c|c|c|}
\hline \multicolumn{2}{|c|}{ Labour 48 Hours or Less } & \multicolumn{2}{|c|}{ Labour Over 48 Hours } \\
\hline $\begin{array}{c}\text { Spontaneous } \\
\text { Vertex } \\
\text { Deliveries }\end{array}$ & $\begin{array}{c}\text { Complicated } \\
\text { Deliveries }\end{array}$ & $\begin{array}{c}\text { Spontaneous } \\
\text { Vertex } \\
\text { Deliveries }\end{array}$ & $\begin{array}{c}\text { Complicated } \\
\text { Deliveries }\end{array}$ \\
\hline 3 & $\begin{array}{ll}\text { Breech } & 3 \\
\text { Transverse lie } & 1 \\
\text { Bladder-stone } & 1\end{array}$ & 11 & $\begin{array}{l}\text { Transverse lie } \\
\text { Craniotomy ... } \\
\text { Shoulder delay } \\
\text { Perineotomy }\end{array}$ \\
\hline
\end{tabular}

TABLE III

\begin{tabular}{l|c|c|c|c|c}
\hline & $0-24 \mathrm{hr}$. & $24-48 \mathrm{hr}$. & $3-4$ days & $5-6$ days & $7-15$ days \\
\hline $\begin{array}{c}\text { Labour } \\
\begin{array}{c}\text { Delivery-incon- } \\
\text { tinence interval }\end{array}\end{array}$ & 8 & 4 & 10 & 1 & 8 \\
\hline
\end{tabular}

major factor in the aetiology of these difficulties and the subsequent fistulae. Twenty-six of the patients were below $4 \mathrm{ft} .11 \mathrm{in} .(150 \mathrm{~cm}$.) in height, the smallest being $4 \mathrm{ft} .6 \mathrm{in}$. $(137 \mathrm{~cm}$.). The exception was a woman of $5 \mathrm{ft} .4 \frac{1}{2}$ in. $(164 \mathrm{~cm}$.) with a true conjugate of $10 \mathrm{~cm}$. who had a transverse lie with a prolapsed arm. None showed external evidence of rickets, nor was any rickety pelvis found at examination under anaesthesia. All had

*Present address: Western Infirmary, Glasgow. 